\title{
Yield and Related Components of Cotton (Gossypium hirsutum L.) Effected by Chlorophyll Contents
}

\section{Muhammad Rizwan ${ }^{1 *}$, Jehanzeb Farooq ${ }^{1}$, Amjad Farooq ${ }^{1}$, Muhammad Farooq, ${ }^{1,2}$, Ghulam Sarwar ${ }^{1}$, Muhammad Nadeem ${ }^{1}$, Muhammad Riaz ${ }^{4}$, Muhammad Rafique Shahid ${ }^{3}$, Hafiz Ghazanfar Abbas ${ }^{1}$ and Muhammad Kashif Shahzad Sarwar ${ }^{1}$}

${ }^{1}$ Cotton Research Station, Ayub Agricultural Research Institute, Faisalabad, Pakistan; ${ }^{2}$ School of Biology and Environmental Science, Science and Engineering Faculty, Queensland University of Technology, Brisbane, Australia; ${ }^{3}$ Cotton Research Institute, Multan, Pakistan; ${ }^{4}$ Wheat Research Institute, Ayub Agricultural Research Institute, Faisalabad, Pakistan.

\begin{abstract}
To study the relationship amongst leaf chlorophyll contents, yield and related parameters, 18 advanced genotypes of cotton were tested in a trial at Cotton Research Station, Faisalabad. Highly significant results were noticed in the analysis of variance. Further investigation in correlation analysis revealed that there was comendable positive association among leaf chlorophyll contents, seed cotton yield (SCY), No. of sympodia, seed index and boll weight $(\mathrm{g})$. Principal Component Analysis (PCA) demonstrated that only 02 out of $08 \mathrm{PCs}$ showed eigen value greater than 1 . The contribution of first two PCs in total variability was $70.77 \%$ amongst the genotypes assessed for chlorophyll contents, seed cotton yield and related traits. Remaining six components contributed very less viz. 30.8\% in total variability. Valuable positive factor loadings on PC I was attributed by seed cotton yield, chlorophyll contents, boll weight, No. of sympodia, seed index and Ginning out turn (GOT)\%. In PC II, maximum positive contribution was presented by plant height whereras maximum negative factor loadings were showed by GOT \% and seed index. PCA also confirmed the results of correlation studies by presenting significant positive association among leaf chlorophyll contents, seed cotton yield, No. of sympodia, seed index and boll weight. These results will be helpful in further breeding strategies for selection of genotypes with respect to chlorophyll contents, yield and associated traits.

Received | March 31, 2021; Accepted | August 13, 2021; Published | January 19, 2022

*Correspondence | Muhammad Rizwan, Cotton Research Station, Ayub Agricultural Research Institute, Faisalabad, Pakistan; Email: muhammadrizwan29@gmail.com

Citation | Rizwan, M., J. Farooq, A. Farooq, M. Farooq, G. Sarwar, M. Nadeem, M. Riaz, M.R. Shahid, H.G. Abbas and M.K.S. Sarwar. 2022. Yield and related components of cotton (Gossypium hirsutum L.) effected by chlorophyll contents. Pakistan Journal of Agricultural Research, 35(1): 29-35.

DOI | https://dx.doi.org/10.17582/journal.pjar/2022/35.1.29.35

Keywords | Yield, Chlorophyll contents, Association, Variability, Cotton
\end{abstract}

\section{Introduction}

$\mathrm{C}$ otton exhibits great importance for the global economy due to increasing demand for cotton products. It is a major cash crop mostly grown for fiber in Pakistan (Farooq et al., 2014). More than eighty countries of the world grow cotton for edible oil and lint (Shakeel et al.,2011). Main raw material related to textile, livestock and edible oil industries is provided by cotton crop (Ali, 2009). Therefore, development of high yielding cotton strains with better quality parameters is very essential for communities.

Genetic variability is a prerequisite for any breeding program and also most common reason for crop decline is low levels of genetic diversity as reported in 
previous findings (Farooq et al., 2017; Shakeel et al., 2015; McCarty et al., 2005). The genotypes having less diversity are mainly responsible for reduction in yield and quality (Rathinavel, 2017). Variation in genetics of cotton strains with respect to physiological and quality parameters was studied by (Li et al., 2005). Knowledge about genotypes behavior and relationship among yield contributing parameters is necessary to counter yield reducing factors (Latif et al., 2015). Cotton genotypes having high yield may be selected keeping in view the morphological parameters viz. Number of sympodia plant ${ }^{-1}$, Number of boll plant ${ }^{-1}$, Seed cotton weight per boll, Seed index and GOT\% (Salahuddin et al., 2010).

Photosynthetic ability of plants is controlled by chlorophyll contents as light energy is captured by them from the sun (Kocks et al., 1995). Leaf chlorophyll contents value gives major information about photosynthetic capacity of a plant (Cannella et al., 2016; Houborg et al., 2015). Chlorophyll contents may be utilized as a decision-making tool to estimate biomass and crop yield (Liu et al., 2019). It was mentioned in the findings of (Boggs et al., 2003) that leaf chlorophyll contents in cotton presented significant positive correlation with seed cotton yield. Minolta SPAD 502 is a chlorophyll contents meter (CCM) which provide quick and non-destructive analysis of plant $\mathrm{N}$ value and is extensively used to assess chlorophyll contents index of crop plants (Patrick, 2007). The correlation estimates among leaf chlorophyll contents, seed cotton yield and related parameters help in the selection of high yielding strains from existing germplasm (Ali, 2001).

Correlation analysis is used to find out the association among different parameters. If there is significant positive correlation amongst two characters, betterment in one character will employ a significant positive effect on the other trait. Therefore, positively linked characters may be improved by selecting one trait.

Mostly, breeders use PCA for assessment of genetic diversity and is helpful for identification of promising strains in upcoming breeding strategies as it illustrates the significance of prime contributor towards total genetic variation (Rehman et al., 2015; Sharma, 2006). Previous studies indicate that yield is multifarious trait, which is mostly affected by environment. So, selection on the basis of yield contributing parameters will be more fruitful (Karademir et al., 2009). This study is helpful in finding out the relationship of chlorophyll contents in regard to seed cotton yield and related parameters and to extract major contributors of total genetic divergence. Findings of this study may be utilized in developing promising cotton genotypes with superior yield contributing traits.

\section{Materials and Methods}

\section{Experimental material and site characteristics}

The experiment was performed during 2019-20 at the research farm of Cotton Research Station Faisalabad, Punjab, Pakistan with $184 \mathrm{~m}$ altitude at $31^{\circ} 21^{\prime} 52^{\prime \prime} \mathrm{N}$ $72^{\circ} 59^{\prime} 40^{\prime \prime}$ E. Plant material comprised of seventeen cotton strains along with one check viz. 419/19, 504/19, 492/19, 495/19, 498/19, 453/19, 455/19, $503 / 19,506 / 19,507 / 19,510 / 19,511 / 19,452 / 19$, 458/19, 6028/17, 6038/17, 6061/17 and FH-142. The sowing was made with hand chopa method on $1^{\text {st }}$ of May, 2019.

\section{Design of experiment}

The experimental was managed in completely randomized block design having two replicates. Measurement of each plot was $4.54 \mathrm{~m} \times 3.03 \mathrm{~m}$, which contained four rows $75 \mathrm{cms}$ apart. Plant into plant distance was kept $30 \mathrm{cms}$. Recommended practices for irrigation, pesticide, weedicides and fertilizer applications were followed as per requirement.

\section{Traits measurement}

For data collection, 10 guarded plants were randomly selected in each entry. The studied traits include: boll weight (g), chlorophyll contents, GOT \%, number of boll plant ${ }^{-1}$, number of sympodia plant ${ }^{-1}$, plant height $(\mathrm{cm})$, seed cotton yield $\left(\mathrm{kg} \mathrm{ha}^{-1}\right)$ and seed index. Data regarding chlorophyll contents, number of boll plant ${ }^{-1}$, number of sympodia plant ${ }^{-1}$ and plant height $(\mathrm{cms})$ were obtained from ten selected plants while seed cotton yield was obtained on plot basis. Fifty open bolls were hand-picked at maturity from each plot for calculation of boll weight, GOT \% and seed index. GOT \% was obtained by using below mentioned equation:

$$
\text { GOT } \%=\frac{\text { Lint Weight }}{\text { Seed Cotton Weight }} \times 100
$$

The chlorophyll meter, Minolta SPAD-502 was used for determination of Leaf chlorophyll contents 
during $2^{\text {nd }}$ week of flowering. Following (Johnson and Saunders, 2003), the reading of leaf chlorophyll contents was taken from $5^{\text {th }}$ fully expanded leaf below the terminal of plant.

The statistical software, Statistix 8.1 was used for obtaining analysis of variance and correlation among studied parameters of different genotypes. Principal Component Analysis (PCA) was performed using Origin 2018 (Moberly et al., 2018).

\section{Results and Discussion}

The significant differences were present among different strains for all of the studied parameters as indicated in analysis of variance (Table 1). The information obtained from correlation and PCA was used by (Khan et al., 2017) to evaluate the exotic lines of cotton for assessment of genetic variability in different yield contributing and quality traits.

\section{Correlation studies}

Correlation analysis results for chlorophyll contents, seed cotton yield and relating parameters are illustrated in Table 2. As depicted in correlation coefficients, leaf chlorophyll contents contributed with significant positive correlation towards boll weight, number of sympodial branches plant ${ }^{-1}$, seed index and seed cotton yield while it correlated negatively with number of boll plant ${ }^{-1}$. As reported by (Reddy and Kumari, 2004), the chlorophyll contents have noteworthy positive relationship with yield and number of boll per plant at phenotypic and genotypic level which indicates the chances of improvement in these characters. While studying the association among leaf chlorophyll contents and yield for different cotton strains and other field crops, significant positive correlation was observed by (Karademir et al., 2009; Gutiérrez et al., 2004; Boggs et al., 2003; Bronson et al., 2003; Ramesh et al., 2002; Kabanova and Chaika, 2001; Araus et al., 1998; Feibo et al., 1998). Grain yield of rice was significantly linked with leaf chlorophyll contents (Ramesh et al., 2002).

Boll weight $(\mathrm{g})$ showed noticeable positive relationship with leaf chlorophyll contents, seed index, No. of sympodial branches plant ${ }^{-1}$ and seed cotton yield. Other traits presented non-significant positive correlation with boll weight except plant height which have negative but non-significant correlation with boll weight. Some scientists also reported indirect significant effect of leaf chlorophyll on seed cotton yield (Reddy and Kumari, 2004).

The percentage Ginning out-turn (GOT) presented significant positive association with number of sympodialbranchesandseedindexwhilenon-significant contribution was observed with all other parameters.

Table 1: The analysis of variance for chlorophyll contents, yield and related components.

$\begin{array}{llllllllll}\text { Source } & \text { DF } & \text { BW } & \text { CHL } & \text { GOT } & \text { NBP } & \text { NSB } & \text { PH } & \text { SCY } & \text { SI } \\ \text { REP } & 1 & 0.02351 & 1.77778 & 0.66694 & 0.0278 & 4.0000 & 7.111 & 72 & 0.00640 \\ \text { TRT } & 17 & 0.44702^{* *} & 6.04418^{* *} & 5.23243^{* *} & 59.2631^{* *} & 39.5817^{* *} & 689.582^{* *} & 189385^{* *} & 0.09218^{* *} \\ \text { Error } & 17 & 0.00276 & 0.24146 & 0.35989 & 4.4395 & 3.2941 & 25.464 & 1657 & 0.01241\end{array}$

*p<0.05, ** <0.01; BW: Boll weight (g), CHL: Chloropyll content (SPAD reading); GOT: (Ginning out turn \%); NBP: Number of boll per plant; NSB: Number of sympodial branches (no/plant), PH: Plant height (cm), SCY: Seed cotton yield (kg ha $\left.{ }^{-1}\right)$; SI: (Seed Index).

Table 2: Correlation coefficients amongst leaf chlorophyll contents, yield and related components of upland cotton.

$\begin{array}{llllllll} & \text { BW } & \text { CHL } & \text { GOT } & \text { NBP } & \text { NSB } & \text { PH } & \text { SCY } \\ \text { CHL } & 0.8485^{* *} & & & & & \\ \text { GOT } & 0.2617 & 0.1967 & & & & \\ \text { NBP } & 0.1623 & -0.0468 & 0.1088 & & & \\ \text { NSB } & 0.7281^{* *} & 0.6591^{*} & 0.4828^{*} & 0.1031 & & & \\ \text { PH } & -0.0823 & -0.0664 & -0.4117 & -0.1907 & 0.1941 & & \\ \text { SCY } & 0.8506^{* *} & 0.9106^{* *} & 0.3194 & 0.0055 & 0.7824^{* *} & -0.0366 & \\ \text { SI } & 0.5007 & 0.6607^{*} & 0.6099^{* *} & 0.0486 & 0.5962^{*} & -0.2865 & 0.7392^{* *}\end{array}$

${ }^{*} p<0.05, * * 0.01 ;$ BW: Boll weight (g), CHL: Chloropyll content (SPAD reading); GOT: (Ginning out turn \%); NBP: Number of boll per plant; NSB: Number of sympodial branches (no/plant), PH: Plant height (cm), SCY: Seed cotton yield (kg ha ${ }^{-1}$ ); SI: (Seed Index). 
In previous studies (Farooq et al., 2014) also reported similar findings of GOT \% with sympodial branches. Plant height presented non-significant negative association with chlorophyll contents, seed cotton yield and related parameters except with sympodial branches which indicates that selection of medium stature genotypes will be helpful in yield improvement. Seed index also correlated positively and significantly with boll weight, chlorophyll contents, GOT, sympodia and seed cotton yield.

Highly positive and significant association of seed cotton yield was observed with boll weight, leaf chlorophyll contents, number of sympodia plant ${ }^{-1}$ and seed index which specifies that the yield can be upgraded by improving these parameters. These studies are in accordance with (Farooq et al., 2014, 2018; Karademir et al., 2009) who mentioned significant positive association of leaf chlorophyll and yield with yield contributing traits.

Table 3: Principle component analysis for chlorophyll contents and yield related traits in upland cotton.

\begin{tabular}{llll}
$\begin{array}{l}\text { Principal com- } \\
\text { ponents }\end{array}$ & Eigenvalue & Variance \% & $\begin{array}{l}\text { Cumulative } \\
\text { variance \% }\end{array}$ \\
\hline 1 & 4.17652 & $52.21 \%$ & $52.21 \%$ \\
2 & 1.48474 & $18.56 \%$ & $70.77 \%$ \\
3 & 0.98812 & $12.35 \%$ & $83.12 \%$ \\
4 & 0.7715 & $9.64 \%$ & $92.76 \%$ \\
5 & 0.3558 & $4.45 \%$ & $97.21 \%$ \\
6 & 0.10039 & $1.25 \%$ & $98.46 \%$ \\
7 & 0.06459 & $0.81 \%$ & $99.27 \%$ \\
8 & 0.05835 & $0.73 \%$ & $100.00 \%$
\end{tabular}

Table 4: Factor loadings by various traits.

$\begin{array}{lll}\text { Variable } & \text { PC1 } & \text { PC2 } \\ \text { Boll weight } & 0.42754 & 0.14277 \\ \text { Chlorophyll contents } & 0.43407 & 0.20015 \\ \text { Ginning out Turn \% } & 0.2618 & -0.50394 \\ \text { Number of boll per plant } & 0.0583 & -0.33374 \\ \text { Number of sympodial branches } & 0.41764 & 0.16275 \\ \text { Plant height } & -0.07549 & 0.68939 \\ \text { Seed cotton yield } & 0.46309 & 0.16087 \\ \text { Seed Index } & 0.40284 & -0.21585\end{array}$

\section{Principal component analysis}

It was revealed in Principal Component Analysis that from 08 principal components (PCs), only 2 showed eigen value greater than 1 (Figure 1). The contribution of first two PCs was $70.77 \%$ in total variation among the strains explored for chlorophyll contents, yield and yield related components (Table 3 , Figure 3). While, the left over six components presented only $29.23 \%$ contribution towards the total diversity. Maximum factor loadings was presented by PC-I (52.21\%) followed by PC-II (18.56\%). This indicates that maximum information about genetic diversity among genotypes is present in first two principal components which may be utilized in further selection. In previous studies of different characters, Saeed et al. (2014) found major impact of first two PCs in the total diversity. As depicted in Table 4, seed cotton yield contributed with maximum positive loading on PC-I subsequently chlorophyll contents, boll weight, No. of sympodia, seed index and GOT\% but plant height had negative loadings. PC-II exhibited maximum positive loadings by plant height subsequently chlorophyll contents and seed cotton yield whereas GOT\% presented maximum negative loadings followed by No. of boll plant ${ }^{-1}$ and seed index. The PC analysis inveterate the amount of diversity for studied traits which may be used in scheming a breeding strategy to improve No. of boll plant ${ }^{-1}$, No. of sympodia plant $^{-1}$, boll weight and consequently seed yield of cotton (Nazir et al., 2013). Principal component analysis was used for assessment of genetic variation regarding physiological parameters of cotton ( $\mathrm{Li}$ et al., 2008). In biplot, the parameters and strains were super-imposed on the graph as vector (Figure 2) and contribution of each parameter with respect to different strains was estimated by their distance on PC-1 and PC-2. While studying different cotton strains, (Saeed et al., 2014), also observed main contribution of first two principal components in variation. As depicted in biplot, the traits boll weight, chlorophyll contents, sympodia, seed cotton yield and seed index added maximum contribution in variation among the explored strains. The strength of correlation among characters was also revealed in biplot. Therefore, it was illustrated that boll weight, chlorophyll contents, sympodia, seed cotton yield and seed index have strong positive correlation with each other. These parameters may be considered in further selection for yield improvement. Shakeel et al. (2015), also found the importance of PCA for selection of desirable strains presenting better quality and yield. PCA is very useful tool as it discloses the significance of major contributors in the diversity present at each level (Sharma, 2006). 


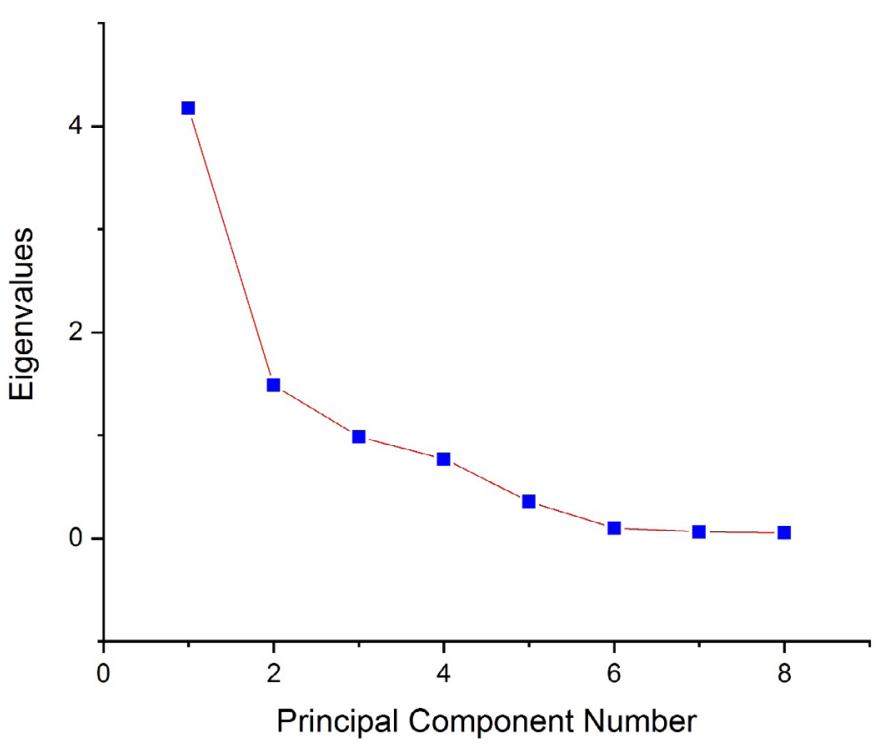

Figure 1: Scree plot

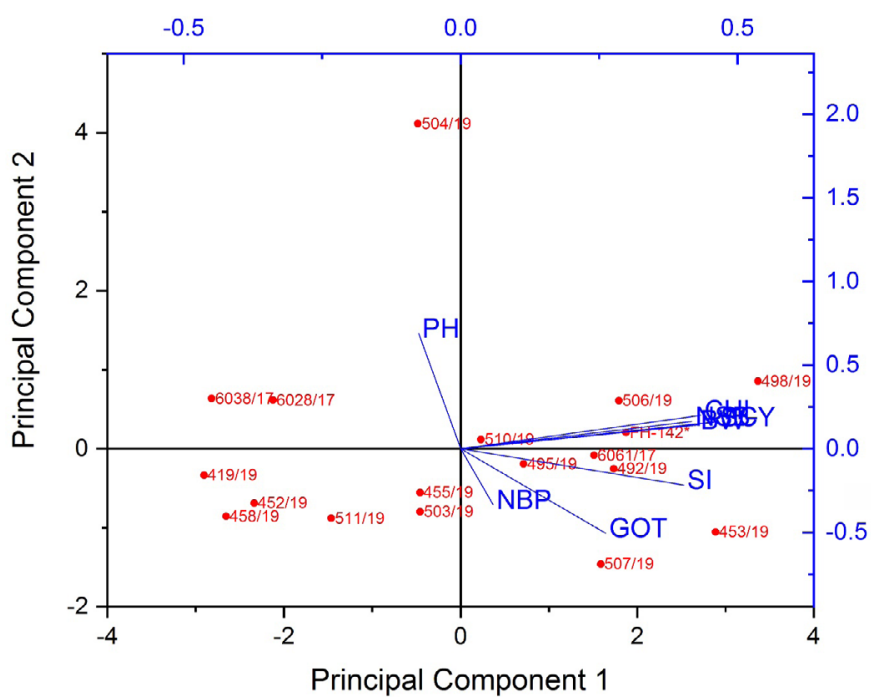

Figure 2: Biplot between PC1 and PC2 shorwing extent of variation.

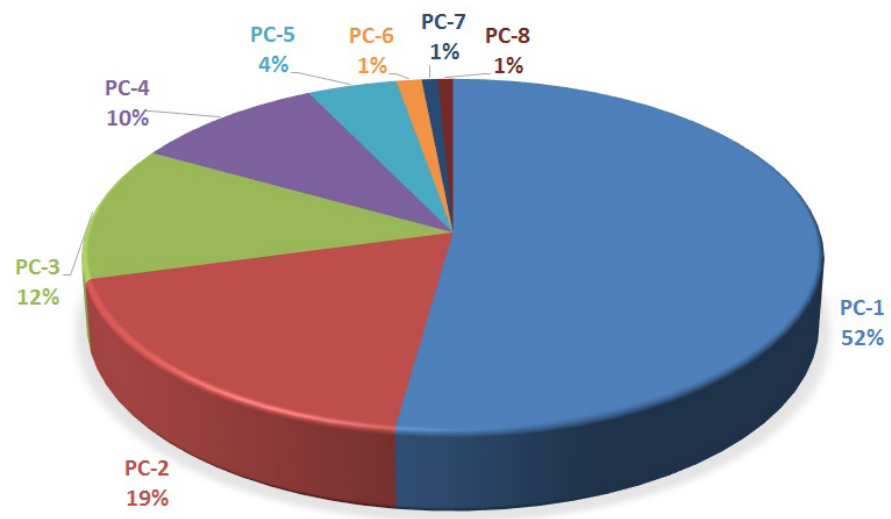

Figure 3: Variance \% exhibited by principle components.

The genotypes 506/19, 498/19, 6061/17, 492/19 and FH-142 have good potential for leaf chlorophyll contents, No. of sympodial branches plant ${ }^{-1}$, seed cotton yield and boll weight while the strains 419/19, 452/19 and 458/19 have less potential for these traits (Figure 2). While considering seed index, the genotypes 6061/17, 492/19 and 453/19 have good potential whereas the genotypes 6038/17 and 6028/17 have minimum potential. Maximum potential for GOT\% and No. of bolls per plant was presented by $507 / 19$. The explored genotypes may further be utilized in hybridization programmes for improvement in related traits.

\section{Conclusions and Recommendations}

The present investigation concluded that the explored genotypes of cotton viz., 506/19, 498/19, 6061/17, 492/19, 453/19, 507/19 and FH-142 have combination of desirable yield contributing parameters and chlorophyll contents. Therefore, these genotypes may be utilized in future breeding practices for incorporation of desirable yield related characters and chlorophyll contents. There was noteworthy correlation among leaf chlorophyll contents, seed cotton yield, No. of sympodial branches plant ${ }^{-1}$, seed index and boll weight which may be considered as selection criteria in future breeding strategies.

\section{Novelty Statement}

The explored cotton genotypes having best combination of yield related components and chlorophyll contents may be utilized for incorporation of desirable characters in future breeding strategies.

\section{Author's Contribution}

Muhammad Rizwan: Conducted research and collected data.

Jehanzeb Farooq: Helped in managing crop and gave useful technical input.

Amjad Farooq: Collected the literature.

Muhammad Farooq: Helped in write up of manuscript.

Ghulam Sarwar: Supervised the study.

Muhammad Nadeem: Helped in data collection.

Muhammad Riaz: Concluded the research.

Muhammad Rafique Shahid: Performed the statistical analysis.

Hafiz Ghazanfar Abbas: Helped in data analysis.

Muhammad Kashif Shahzad Sarwar: Managed references.

\section{Conflict of interest}

The authors have declared no conflict of interest. 
Ali, M.A., A. Abbas, M. Younas, T.M. Khan and H.M. Hassan. 2009. Genetic basis of some quantitative traits in upland cotton. Plant Omics J., 2: 91-97.

Ali, S.E., 2001. Study of morphological traits and genetic variation in different genotypes of upland cotton (Gossypium birsutum L.) in Iran. Seed Plant Improv. J., 17: 44-60.

Araus, J.L., T. Amaro, J. Voltas, H. Nakkoul and M.M. Nachit. 1998. Chlorophyll Fluorescence as a selection criterion for grain yield in durum wheat under Mediterranean conditions. Field Crop. Res., 55: 209-223. https://doi. org/10.1016/S0378-4290(97)00079-8

Boggs, J.L., T.D. Tsegaye, T.L. Coleman, K.C. Reddy and A. Fahsi. 2003. Relationships between hyperspectral reflectance, soil nitratenitrogen, cotton leaf chlorophyll and cotton yield: A step toward precision agriculture. J. Sustain. Agric., 22(3): 5-16. https://doi. org/10.1300/J064v22n03_03

Bronson, K.V., T.T. Chua, J.D. Booker, J.W. Keeling and R.J. Lascano. 2003. In-Season nitrogen status sensing in irrigated cotton. II. Leaf nitrogen and Biomass. Soil Sci. Soc. Am. J., 67: 1439-1448. https://doi.org/10.2136/ sssaj2003.1439

Cannella, D., K.B. Mollers, N.U. Frigaard, P.E. Jensen, M.J. Bjerrum, K.S. Johansen and C. Felby. 2016. Light driven oxidation of polysaccharides by photosynthetic pigments and a metalloenzyme. Nat. Commun., 7: 11134. https://doi.org/10.1038/ncomms11134

Farooq, J., M. Anwar, M. Riaz, A. Farooq, A. Mahmood, M.T.H. Shahid, M.R. Shahid and F. Ilahi. 2014. Correlation and path coefficient analysis of earliness, fiber quality and yield contributing traits in cotton (Gossypium birsutum L.). JAPS, 24(3): 781-790.

Farooq, J., M. Rizwan, I. Sharif, S. Saleem, S.M. Chohan and R.A. Kainth. 2017. Genetic diversity studies in some advanced lines of Gossypium hirsutum L. for yield and quality related attributes using cluster and principle component analysis. A. A. Bioflux., 9(3): 111118.

Farooq, J., M. Rizwan, S. Saleem, I. Sharif, S.M. Chohan, M. Riaz, F. Ilhai and R.A. Kainth. 2018. Determination of genetic variation for of cotton (Gossypium hirsutum). Adv. Agric. Sci., 6(2): 59-74.

Feibo, W., W. Lianghuan and X. Fuhua. 1998. Chlorophyll meter to predict nitrogen sidedress requirements for short-season cotton (Gossypium hirsutum L.) Field Crop Res., 56(3): 309-314. $\quad$ https://doi.org/10.1016/S03784290(97)00108-1

Gutiérrez-Rodríguez, M.G., M.P. Reynolds, J.A. Escalante-Estrada and M.T. RodríguezGonzález. 2004. Association between canopy reflectance indices and yield and physiological traits in bread wheat under drought and wellirrigated conditions. Aust.J. Agric. Res., 55(11): 1139-1147. https://doi.org/10.1071/AR04214

Houborg, R., M. McCabe, A. Cescatti, F. Gao, M. Schull and A. Gitelson. 2015. Joint leaf chlorophyll content and leaf area index retrieval from land sat data using a regularized model inversion system (regflec). Remote Sens. Environ., 159: 203-221. https://doi. org/10.1016/j.rse.2014.12.008

Johnson,J.R. and J.R. Saunders.,2003.Evaluation of Chlorophyll Meter for Nitrogen Management in Cotton. http://msucares.com/nmrec/ reports/2002/.

Kabanova, S.N. and M.T.Chaika.2001. Correlation Analysis of Triticale Morphology, Chlorophyll Content and Productivity. J. Agron. Crop Sci., 186(4): 281-285. https://doi.org/10.1046/ j.1439-037x.2001.00481.x

Karademir, C., E. Karademır, R. Ekıncı and O. Gencer. 2009. Correlations and path coefficient analysis between leaf chlorophyll content, yield and yield components in cotton (Gossypium birsutum L.) under drought stress conditions. Not. Bot. Hort. Agrobot. Cluj-Nap., 37(2): 241-244.

Khan, M.I., H.A. Haq, K. Ullah, M. Arshad and A. Majid. 2017. Genetic diversity and correlation studies for cotton leaf curl disease (CLCuD), fiber and yield related attributes in exotic lines of Gossypium arboreum L. Am. J. P1. Sci., 8: 615624. https://doi.org/10.4236/ajps.2017.83042

Kocks, P., J., Ross and O. Bjorkman. 1995. Thermodynamic efficiency and resonance of photosynthesis in a c3 plant. J. Phys. Chem., 99: 16483-16489. https://doi.org/10.1021/ j100044a043

Latif,A.,M.Bilal, S.B.Hussain and F.Ahmad.2015. 
Estimation of genetic divergence, association, direct and indirect effects of yield with other attributes in cotton (Gossypium birsutum L.) using biplot correlation and path coefficient analysis. Trop. Plant Res., 2(2): 120-126.

Li, R.I., Z. Long and J. Chen. 2005. Comparison of fiber quality characteristics of different varieties of hybrid cotton. J. Hunan. Agric. Univ., 31: 492-495.

Li, Z., X. Wang, Z. Yan, Z. Guiyin, L. Wu, C. Jina and Z.Ma.2008. Assessment of genetic diversity in glandless cotton germplasm resources by using agronomic traits and molecular markers. Front. Agric. China, 2: 245-252. https://doi. org/10.1007/s11703-008-0063-X

Liu, C., Y. Liu, Y. Lu, Y.L. Liao, J. Nie, X. Yuan and F. Chen. 2019. Use of a leaf chlorophyll content index to improve the prediction of above-ground biomass and productivity. Peer J., 6: e6240. https://doi.org/10.7717/peerj.6240

McCarty,J.C.,J.N.Jenkins andJ.Wu.2005.Primitive accession derived germplasm by cultivar crosses as sources for cotton improvement. Crop Sci., 44: 1231-1235. https://doi.org/10.2135/ cropsci2004.1231

Moberly, J.G., M.T. Bernards and K.V. Waynant. 2018. Key features and updates for Origin 2018. J. Chem. Inf., 10(5): 1-2. https://doi. org/10.1186/s13321-018-0259-x

Nazir, A., J. Farooq, A. Mahmood, M. Shahid and M. Riaz. 2013. Estimation of genetic diversity for $\mathrm{CLCuV}$, earliness and fiber quality traits using various statistical procedures in different crosses of Gossypium hirsutum L. Vestnik Orel G.A.U., 4(43): 2-9.

Patrick, D.B., 2007. Evaluating a chlorophyll content meter on three coastal wetland plant species. J. Agric. Food Environ. Sci., 1(2): 1-11.

Ramesh, K., B. Chandrasekaran, T.N. Balasubramanıan, U. Bangarusamy, R. Sivasamy and N. Sankaran. 2002. Chlorophyll dynamics in rice (Oryza sativa) before and after flowering based on SPAD (Chlorophyll) meter monitoring and its relation with grain yield.J. Agron. Crop Sci.,
188: 102-105. https://doi.org/10.1046/j.1439037X.2002.00532.X

Rathinavel, K., 2017. Exploration of genetic diversity for qualitative traits among the extant upland cotton (Gossypium hirsutum L.) varieties and parental lines. Int. J. Curr. Microbiol. App. Sci.,6(8):2407-2421.https://doi.org/10.20546/ ijcmas.2017.608.285

Reddy, A.N. and S.R. Kumari. 2004. Association of Physiological parameters with yield and yield components in American cotton (Gossypium hirsutum L.) Madras Agric. J., 91(7-12): 515518.

Rehman, S.U., M.A. Abid, M. Bilal, J. Ashraf, S. Liaqat, R.I. Ahmed and G. Qanbar. 2015. Genotype by trait analysis and estimates of heritability of wheat (Triticum aestivum L.) under drought and control conditions. Basic Res. J. Agric. Sci. Rev., 4(4): 127-134.

Saeed, F., J. Farooq, A. Mahmood, M. Riaz, T. Hussain and A. Majeed. 2014. Assessment of genetic diversity for Cotton leaf curl virus $(\mathrm{CLCuD})$, fiber quality and some morphological traits using different statistical procedures in Gossypium birsutum L. Aust. J. Crop Sci., 8(3): 442-447.

Salahuddin, S., S. Abro, M.M. Kandhro, L. Salahuddin and S. Laghari. 2010. Correlation and path coefficient analysis of yield components of upland cotton (Gossypium birsutum L.) Sympodial. World Appl. Sci. J., 8 (Special Issue of Biotech. and Genet. Engineer.): 71-75.

Shakeel, A., I. Talib, M. Rashid, A. Saeed, K. Ziaf and M.F. Saleem. 2015. Genetic diversity among upland cotton genotypes for quality and yield related traits. Pak. J. Agric. Sci., 52: 73-77. Shakeel,A.,J.Farooq, M.A.Ali,M. Riaz,A. Farooq, A. Saeed and M.F. Saleem. 2011. Inheritance pattern of earliness in cotton (Gossypium birsutum L.). Aust. J. Crop Sci., 5: 1224-1231.

Sharma, J.R., 2006. Statistical and biometrical techniques in plant breeding, New Age International Publishers. pp. 432. 